\section{Open Hearth Furnace Models}

A DESCRIPTION was given in a letter in Nature of March 27, p. 479, of the use of aluminium powder for flow visualization in a water model of an open hearth furnace. It has since been shown that part of the pattern was due to air bubbles, and that if these are eliminated the aluminium shows up as extremely short light streaks due to the rapidly changing orientation of the disk-shaped particles during the exposure period.

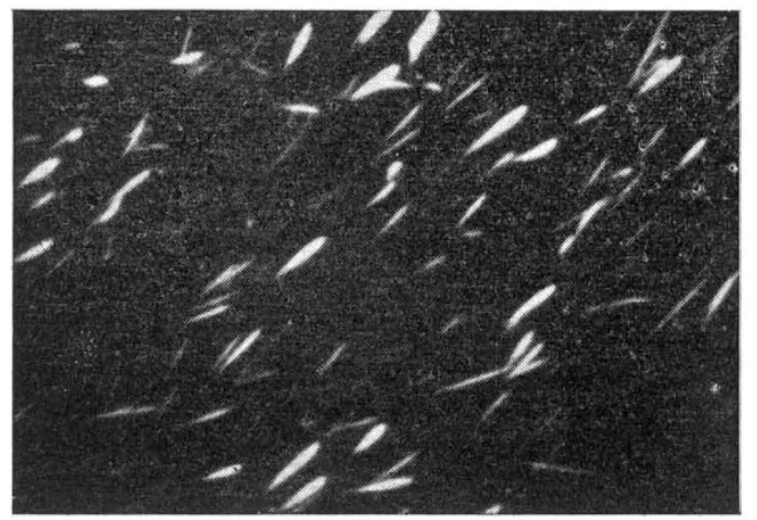

At the suggestion of Mr. F. H. Saniter, director of research, further tests were made in which a stream of gas (initially oxygen) was introduced into the water before the 'checkers', after all the original bubbles had been eliminated by suitable adjustment of the control valves. This technique resulted in an immediate improvement both in the ease of observation and photographic clarity. Not only were the individual bubble streaks far more clearly discernible, but also the falling off in light intensity of the flash from the discharge tube during the exposure results in a point on the tracks that enables their direction of movement to be easily recognized. This latter feature is proving a great asset in the study of such highly turbulent conditions.

The United Steel Companies, Ltd.,

A. R. PHILrP

Research and Development Department,

Swinden House,

Moorgate, Rotherham.

June 8.

\section{Induced and Spontaneous Abnormality in Ciliates}

MOTTRAM ${ }^{1,2}$, by means of various physical agents and by means of certain cyclic hydrocarbons-all factors, except one of the latter group, said to be carcinogenic-disorganised a ciliate and found some persistence of abnormality in the offspring of the disorganised cells. At first he named the ciliate Paramecium aurelia ${ }^{1}$ and later Paramecium and $P$. colpoda Ehr., but finally adjusted the identification to "an amicronucleate race of Colpidium". It is important to realize that his ciliate, being without a micronucleus, was intrinsically abnormal. In the reaction he suggested an analogy to tumour formation and surmised that where such abnormals arise spontaneously in culture there has been unwittingly some exposure to a carcinogenic factor.
Such abnormalities, the origin of which is in a double cell, have been produced by merotomy ${ }^{3,4}$, by exposure to sodium bromide ${ }^{5}$, hydrogen cyanide ${ }^{6}$, benzene hexachloride ('Gammexane')?, by transfer of a culture to hard chlorinated tap water ${ }^{8}$; also as a sequel to conjugation?.

In the case of 'Gammexane' and Paramecium caudatum, up to a 56 per cent conversion to an abnormal form has been obtained. These double cells become monstrous and multinucleate. They give rise to both normal and abnormal cells, but usually there is no suggestion of persistence of abnormality, which disappears at the death of the primary or secondary abnormal forms. One of ninety such cases closely followed has behaved differently, with constant difficulty in parting of the cells at division, and yielding frequent double cells, various distorted individuals and monsters for six months until the clone was abandoned. The greatest development of abnormals occurred eight to ten weeks after the exposure to 'Gammexane'.
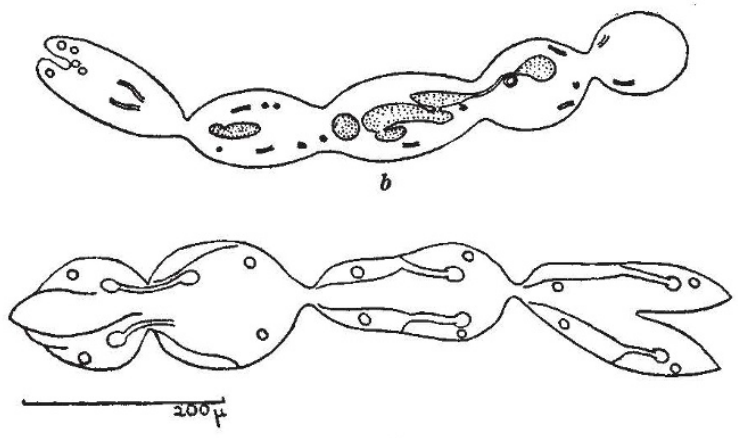

$a$

Chain-forming spontaneous abnormal Paramecium caudatum. $a$, From life, showing doubling of mouths and contractile vacuoles and bifid tendency. $b$, Showing disorganisation of nuclei and intercalary division. Macronuclei are shown stippled, healthy micronuclei as black dots, degenerate ones as circles, gullets as slits

In spite of the fact that this experience was unique in the series, it would have been attributed to a residual effect of the 'Gammexane'; but, about the same time, a double cell appeared in a stock culture which formed part of the control. This spontaneous instance has maintained abnormality in its offspring for more than a year, and the clone is still vigorous though with a morbid tendency. The cells are extremely sticky in division, so that chains of up to nine cells are produced. There is a tendency to bilateral symmetry in organelles, but the nuclei in the chains are completely disorganised (see figure). It gives off normal cells, and normal side-lines can be obtained by selection. In some respects it resembles a case reported by Jennings ${ }^{10}$ which also arose spontaneously but has better viability as the chains will live alone in culture, whereas his died unless normal cells were included to aerate the medium. He recorded no doubling of organelles and did not report on nuclear conditions. The stock cultures, maintained in 0.5 per cent linseed infusion, were exposed to no conceivable carcinogenic agent, and the origin of this abnormal clone was, without doubt, due to some intrinsic cause.

In the light of such observations, the basis of Mottram's hypothesis does not exist. Nevertheless, having regard to the present wide use of benzene hexachloride as an insecticide, it was thought wise 